\title{
Retinal vascular changes in bull's eye maculopathy
}

\author{
AMRESH CHOPDAR \\ From the Fundus Clinic, Moorfields Eye Hospital, London
}

Chloroquine toxicity produces a typical macular degeneration commonly described as 'bull's eye' retinopathy (Hobbs, Sorsby, and Freedman, 1959; Kearns and Hollenhorst, 1966). Since its recognition, similar macular appearances have been described in various other conditions without ingestion of chloroquine (Krill and Deutman, 1972; Deutman, 1974; Weise and Yannuzzi, 1974). One such case is described in this paper and the possible nature of the aetiology is discussed.

\section{Case report}

A 5 I-year-old White woman was seen in the fundus clinic of Moorfields Eye Hospital. She had a history of slow progressive loss of central vision in the right eye during the previous 12 months, but had not found it difficult to adjust to the dim light. Her only son has also been examined and found to have no ocular disease. In the past she had taken fenfluramine to control obesity and at the time of presentation and for the previous four years was taking methaqualone.

\section{OCULAR FINDINGS}

The visual acuity was counting fingers in the right and $6 / 9$ in the left eye. The external slit-lamp examination, including ocular motility, were normal. The fundi showed identical involvement at each macula. The central macular area looked a deeper red than normal and surrounding it a halo-like zone could be seen with many white, shiny, dot-like particles, giving the typical 'bull's eye' phenomenon usually seen in chloroquine retinopathy (Fig. I). These white dots were found to be retinal pigment epithelial defects when examined with a fundus viewing contact lens. The circle of punctate epithelial defect was in turn encircled by a ring of grey retina through which the underlying choroidal vessels could be seen with little difficulty. The peripheral retina in the temporal part of the right eye showed sheathing of vessels with tortuosity and arterio-venous anastomosis. Peripheral to the area of anastomosis there was an abrupt end to the retinal circulation; this was evident from the change in colour between the two zones. The poorly perfused peripheral retina showed several areas of round atrophic patches with pigmented edges (Fig. 2). The left peripheral retina showed sheathing and tortuosity, but no arterio-venous anastomosis.

Address for reprints: A. Chopdar, FRCS, Fundus Clinic, Moorfields Eye Hospital, High Holborn, London WCiV 7AN
Fluorescein angiography showed a confluent punctate fluorescence surrounding a hypofluorescent macula. Around this complex was a faint fluorescent ring corresponding with the grey circle seen clinically (Fig. 3). The peripheral retina in the right eye showed arteriovenous anastomosis and demonstrated the abrupt cessation of the retinal circulation. The round atrophic patches showed transmission defects during the early stages and scleral staining during the later frames (Figs 4, 5).

\section{RETINAL FUNCTION TESTS}

The peripheral field showed some constriction in each eye. There was a central scotoma in the right eye but no such defect was seen in the left. The colour vision was normal in the left eye but could not be tested satisfactorily in the right owing to gross reduction of vision. The electroretinogram showed a scotopic $B$ wave of $130 \mathrm{mV}$ in the right and $200 \mathrm{mV}$ in the left eye. The photopic response of the right eye was present with a good flicker response but the amplitude was significantly lower than in the left eye. Similarly the electro-oculogram was only 155 per cent in the right and 180 per cent in the left eye.

\section{GENERAL PHYSICAL EXAMINATION}

The patient was moderately obese with a blood pressure of $130 / 80 \mathrm{mmHg}$. The cardiovascular, respiratory, abdominal, and central nervous systems were all normal.

\section{LABORATORY INVESTIGATIONS}

The haematological examination showed haemoglobin I $5 \mathrm{~g} / 100 \mathrm{ml}$, packed cell volume 42 per cent, mean cell haemoglobin concentration 36 per cent, total white cell count $9000 / \mathrm{mm}^{3}$, neutrophils 57 per cent, eosinophils 3 per cent, lymphocytes 33 per cent, monocytes 7 per cent, erythrocyte sedimentation rate $5 \mathrm{~mm}$ in $\mathrm{I}$ hour (Westergren), and no gross abnormality in the red blood cells. The biochemical estimation of total serum protein was $7.2 \mathrm{~g} / 100 \mathrm{ml}$, albumin $4.2 \mathrm{~g} / 100 \mathrm{ml}$, globulin $3.0 \mathrm{~g} /$ $100 \mathrm{ml}$ with a normal electrophoretic pattern. The immunoglobulin assay showed a slight increase of IgM at $325 \mathrm{IU} / \mathrm{ml}$ but normal values for IgG, IgA, and IgD. Serological tests for syphilis and Reiter's syndrome were negative.

\section{Discussion}

Maculopathy mimicking chloroquine toxicity in cases of cone dystrophy was described by Krill and 


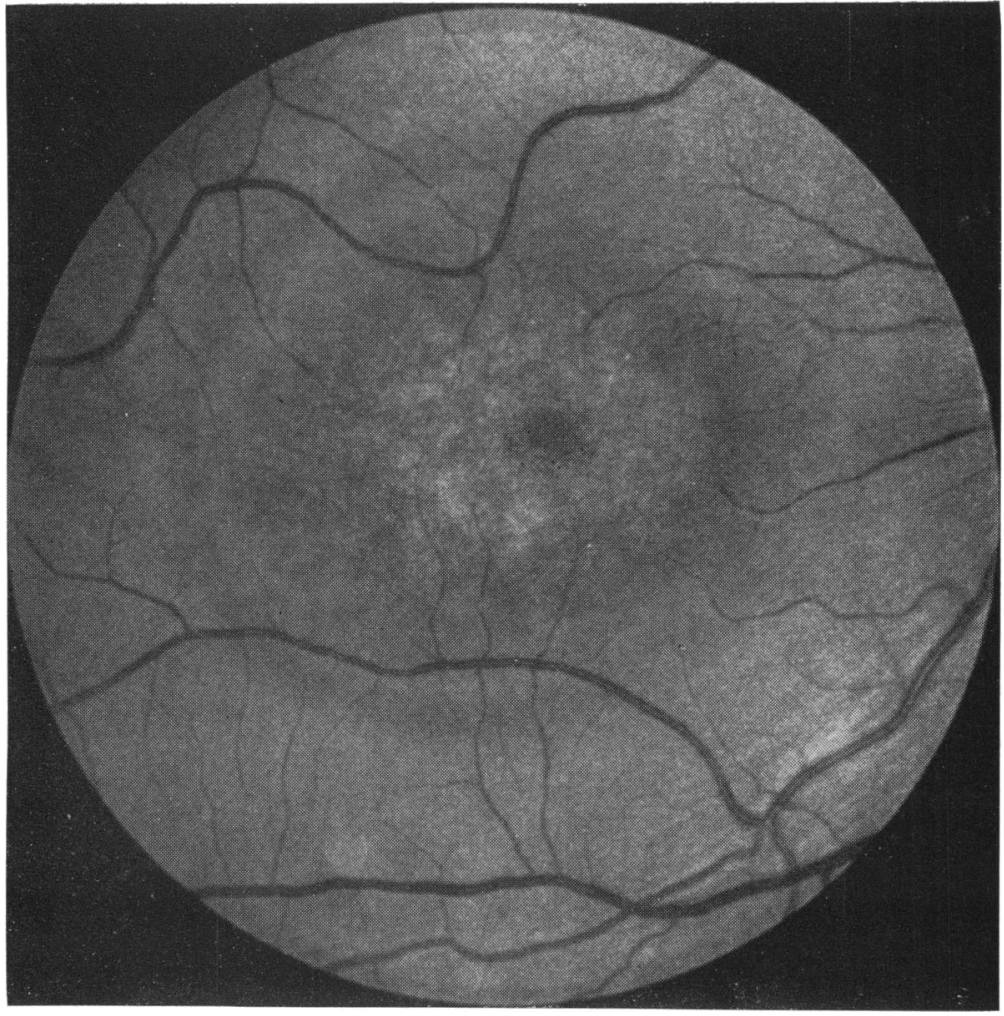

FIG. I Red free photograph of right macula showing a darker fovea, surrounded by many white spots, lying within a ring of grey retina

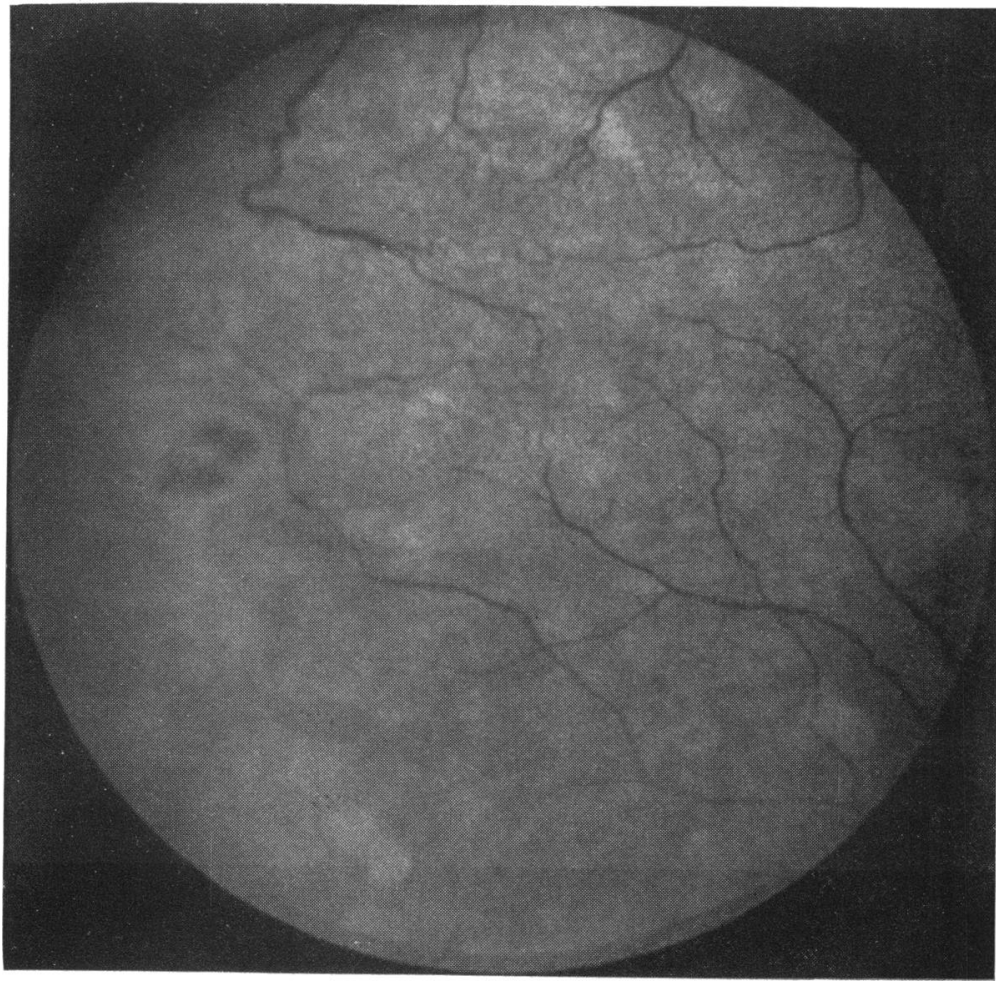

FIG. 2 Red free photograph of right temporal periphery showing vascular abnormalities and poor peripheral retinal circulation

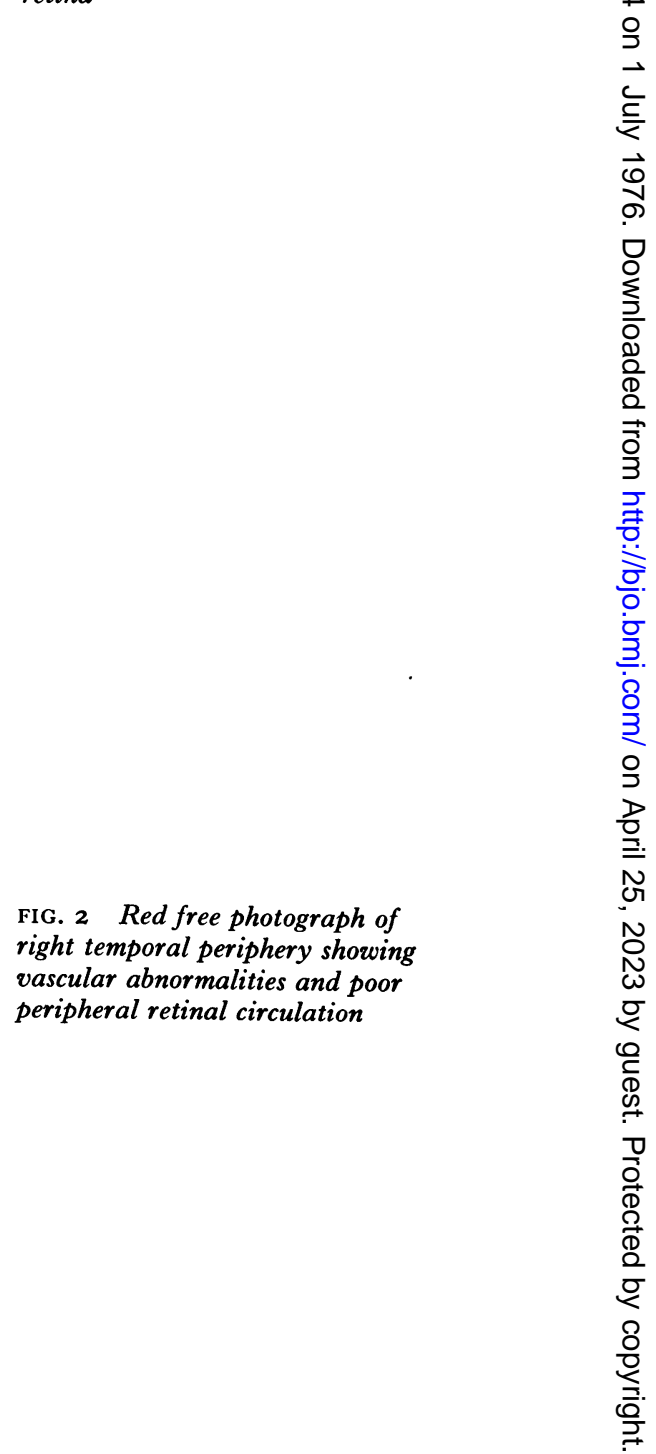




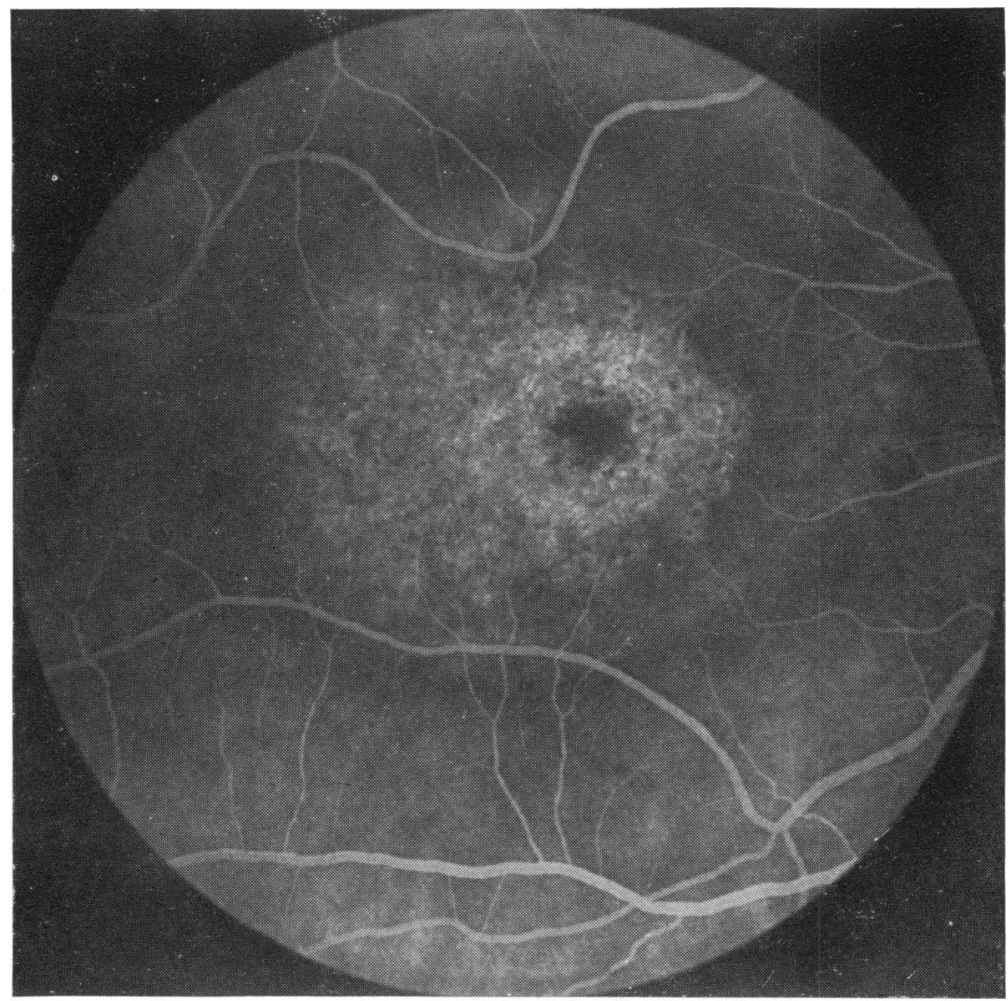

FIG 3 Fluorescein angiography of right macula showing confluent punctate fluorescence surrounding a hypofluorescent fovea, similar to that of chloroquine toxicity

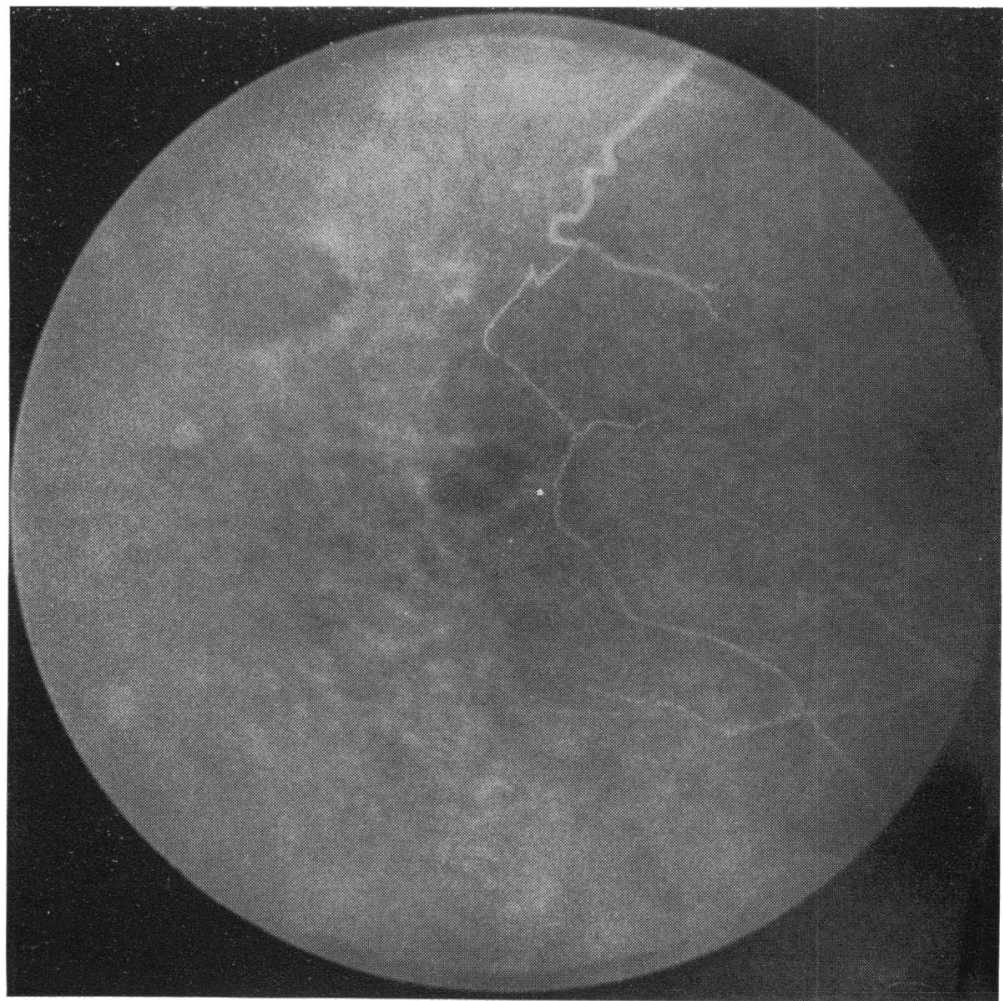

FIG. 4 Fluorescein angiography of right temporal periphery showing arterio-venous anastomosis and poor retinal circulation peripheral to the anastomosis (slightly touched to obtain contrast) 


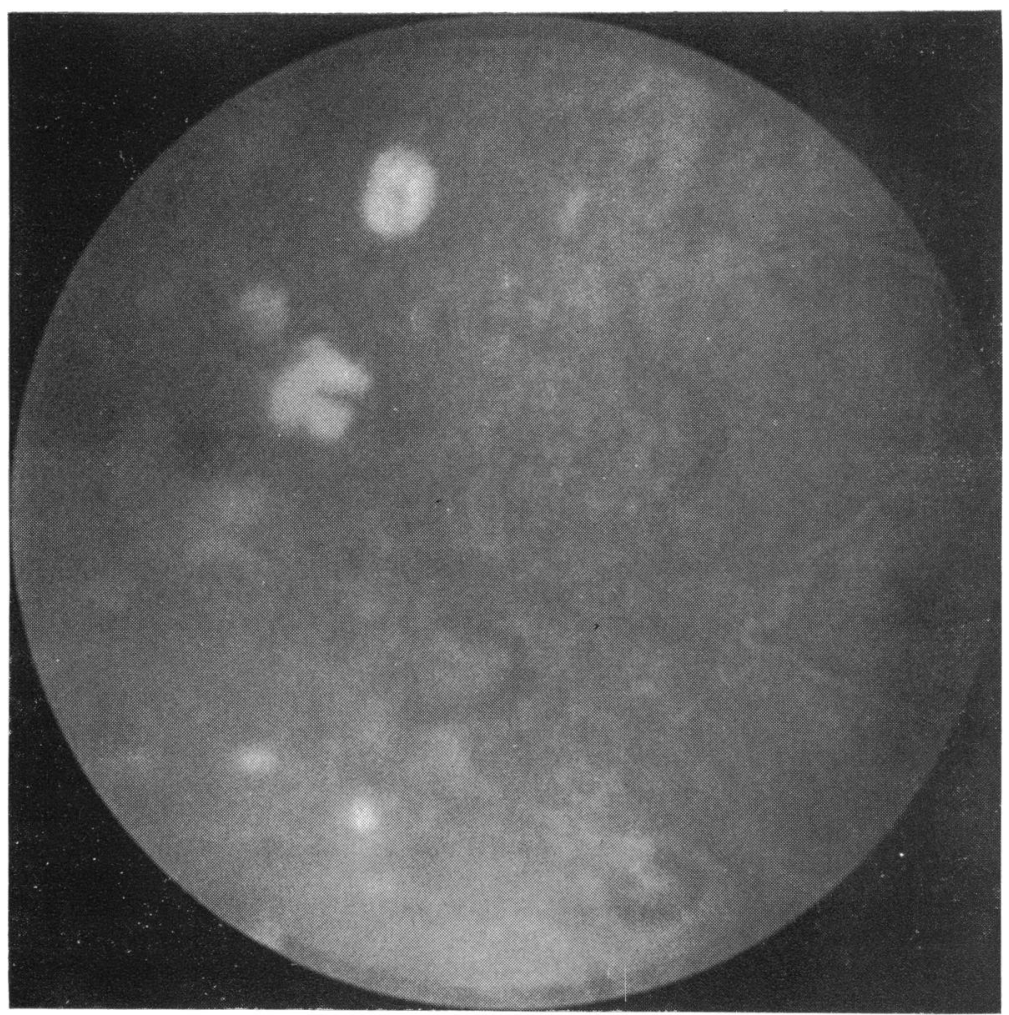

FIG 5 Fluorescein angiography of the right temporal periphery $10 \mathrm{~min}$ after the injection of dye, showing scleral staining of the atrophic patches

Deutman (1972). These patients suffered from severe loss of central and colour vision. Later, Deutman (1974) reported a case of autosomal dominant macular degeneration which he called benign concentric annular macular dystrophy which had similar fluorescein results but good visual acuity. Weise and Yannuzzi (1974) made a fluorescein angiographic study of ring-like transmission defects around the macular area in patients not suffering from chloroquine toxicity and obtained somewhat similar pictures in Stargardt's disease, pre-disciform macular degeneration, and resolved central serous retinopathy; on several occasions the diagnosis was thought to be progressive macular degeneration of unknown aetiology.

The case described here had signs resembling chloroquine toxicity, in addition to the peripheral retinal vascular changes not seen earlier. No instances of toxicity ascribed to methaqualone or fenfluramine have been found in the literature, and genetic evidence is inadequate as the only available relative (the son) is normal. The aetiology remains obscure.

\section{Summary}

A case of maculopathy mimicking chloroquine toxicity without exposure to the drug is described. The peripheral retina showed sheathing and arterio-venous anastomosis with poor perfusion of the retinal circulation.

I thank Professor D. W. Hill for permission to report this case and for his helpful criticism; Mrs Ann Marie Turk for the illustrations, and Mrs Joyce Preen for secretarial help.

\section{References}

Deutman, A. F. (1974) Amer. F. Ophthal., 78, 384

HOBBS, H., SORSBY, A., and FREEDMAN, A. (1959) Lancet, 2, 478

KeARNS, T. P. , and hollenhorst, R. W. (1966) Arch. Ophthal., 76, 378

KRILL, A. E., and DEUTMAN, A. F. (1972) Amer. F. Ophthal., 73, 352

WEISE, E. E., and YANNUZZI, L. A. (1974) Ibid., 78, 204 